\title{
Análise de risco da barragem de minério de ferro na Serra Norte no Pará
}

\author{
Risk analysis of the iron ore dam in the Northern Mountains in Pará
}

Análisis de riesgo de la presa de mineral de hierro en la Sierra Norte de Pará

\section{Resumo}

A mineração é um dos setores responsáveis pelo uso do solo e ocupação do território brasileiro, tem sido essencial para o crescimento econômico do país. O principal crescimento da Região Norte, no estado do Pará, localiza -se na Serra dos Carajás, onde situa - se uma das maiores jazidas de minério de ferro puro do mundo. Por isso é importante a análise de um futuro impacto socioambiental em caso de rompimento da barragem que recebe o estéril da produção de ferro, por meio do fluxo dos rejeitos em um raio de $50 \mathrm{~km}$ da área afetada, utilizando como base às imagens do sensor ALOS PALSAR, com resolução de 12,5 metros. Ao analisar, verifica - se que em caso de rompimento a área afetada primeiramente será Parauapebas devido sua localização, logo após as cidades de Marabá e a região de Canaã, conforme os tipos de elevação demonstrados no mapa, ocasionando impactos ambientais, sociais e até mesmo econômicos, tais efeitos que podem ser irreversíveis e de difícil gestão. De tal modo, para mitigar e prevenir os danos, deve- se fortalecer a legislação através de melhores práticas de governança, programas de monitoramento estruturados, rigorosidade nas leis ambientais, fiscalizações de órgãos ambientais competentes as atividades de barragens e liberação de licenças ambientais.

Palavras-chave: Rompimento; Acidente; Impactos. 


\begin{abstract}
Mining is one of the sectors responsible for land use and occupation of the Brazilian territory, it has been essential for the country's economic growth. The main growth in the North Region, in the state of Pará, is located in Serra dos Carajás, where one of the largest deposits of pure iron ore in the world is located. That is why it is important to analyze a future socio-environmental impact in the event of a collapse of the dam that receives the waste from iron production, through the flow of tailings within a radius of $50 \mathrm{~km}$ from the affected area, using as a basis the images of the ALOS sensor PALSAR, with a resolution of 12.5 meters. Upon analysis, it appears that in case of rupture, the affected area will first be Parauapebas due to its location, right after the cities of Marabá and the Canaã region, according to the types of elevation shown on the map, causing environmental, social and even such effects that can be irreversible and difficult to manage. Thus, to mitigate and prevent damage, legislation must be strengthened through better governance practices, structured monitoring programs, strictness in environmental laws, inspections by competent environmental agencies for dam activities and the release of environmental licenses.
\end{abstract}

Keywords: Disruption; Accident; Impacts.

\title{
Resumen
}

La minería es uno de los sectores responsables del uso y ocupación del suelo del territorio brasileño, ha sido fundamental para el crecimiento económico del país. El principal crecimiento de la Región Norte, en el estado de Pará, se ubica en la Serra dos Carajás, donde se ubica uno de los mayores depósitos de mineral de hierro puro del mundo. Por eso es importante analizar un futuro impacto socioambiental en caso de colapso de la presa que recibe los residuos de la producción de hierro, a través del flujo de relaves en un radio de $50 \mathrm{~km}$ del área afectada, utilizando como base las imágenes del sensor ALOS PALSAR, con una resolución de 12,5 metros. Tras el análisis, parece que en caso de ruptura, el área afectada será primero Parauapebas debido a su ubicación, justo después de las ciudades de Marabá y la región de Canaã, de acuerdo con los tipos de elevación que se muestran en el mapa, causando daños ambientales, sociales y incluso efectos que pueden ser irreversibles y difíciles de manejar. Por lo tanto, para mitigar y prevenir daños, se debe fortalecer la legislación a través de mejores prácticas de gobernanza, programas de monitoreo estructurado, rigor en las leyes ambientales, inspecciones de las agencias ambientales competentes para las actividades de represas y la liberación de licencias ambientales.

Palabras clave: Ruptura; Accidente; Impactos.

\section{Introdução}

As barragens em âmbito global consistem em estruturas em prol do aprimoramento econômico em diversos fatores e produtos. Segundo o Instituto TecnológicoVale (2019), atualmente existem no mundo pouco mais de 56 mil barragens, onde são dispostos basicamente para a acumulação de água, embora também sejam utilizadas para deposição de outros materiais, como rejeitos de processos industriais, no qual estes devem ser feitos de maneira controlada, planejada e segurada, pois o impacto sócio ambiental se torna alarmante, devido aos componentes químicos presentes nos resíduos de forma exacerbada.

A mineração é um dos setores responsável pelo uso do solo e ocupação do território brasileiro e tem sido essencial para o crescimento econômico do país (Thomé \& Passini, 2018). No qual tal fato ocorre desde a produção do ouro e dos diamantes, no período colonial, e com a extração e produção do ferro, no Império e no início da República, aquecendo ainda mais o setor diante do mercado. Todavia, os impactos causados devido a este tipo de exploração possuem como características intrínsecas a rigidez locacional, a modificação do meio ambiente e a geração de riscos socioambientais.

A região amazônica possui uma diversidade de riquezas naturais, o setor da mineração tem sido um dos principais motores de crescimento da Região Norte, especialmente no estado do Pará, com foco principalmente de Serra dos Carajás, que aparece como uma das maiores jazidas do planeta e produz o minério de ferro mais puro do mundo, conforme relata o Sindicato das Indústrias Minerais do Estado do Pará (2019), consequentemente um risco iminente (Silva et al 2020, Caitano et al 2021).

Segundo Guimarães (2018), os impactos ambientais e os riscos mais significativos para a indústria da mineração estão associados às barragens de rejeitos e depósitos de estéril. E, ao longo da história, os acidentes com ruptura de barragens de rejeito não são raros, em alguns casos, são causados por problemas de gestão de segurança (Reis et al 2020, Silva et al 2020, Scarpelin et al 2020). Na pesquisa ambiental, as geotecnologias vem se destacando como um instrumento de grande eficácia pois propicia a obtenção de informações de interesse a partir da integração geoespacial dos dados e modelagem de suas 
interrelações, levando em conta a localização e quantificando as relações espaciais dos fenômenos analisados, visando contribuir para análise e acompanhamento da evolução passada e futura (Rosário et al, 2021, Ribeiro et al 2021, Souza et al 2021, Tavares et al 2021). Diante do exposto, objetivamos demonstrar por meio de imagens via satélite (geoprocessamento), a principal barragem de minério de ferro do estado, analisando um futuro impacto socioambiental em caso de rompimento, em um fluxo do rejeito no raio de $50 \mathrm{~km}$ da área afetada.

\section{Metodologia}

Este trabalho estudou e mapeou o Complexo Minerador de Carajás, especificamente a barragem localizada na Serra Norte de Parauapebas no Estado do Pará, destacando um raio de análise de $50 \mathrm{~km}$, com o intuído de identificar as regiões mais afetadas caso ocorra um desastre de rompimento da barragem, na Figura1 destaca-se a localização da barragem e os municípios englobados, que são: Parauapebas, Canã̃ dos Carajás, Marabá e Curionópolis.

Para o mesmo foi necessário buscar dados altimétricos com o melhor detalhamento da área, por isso foi utilizado como base às imagens do sensor ALOS PALSAR, o radar de abertura sintética (SAR) de banda L, que realizou sua missão de 2006 a 2011, proporcionando uma observação detalhada no modo de feixe FBS de 12,5 metros, de todos os climas, dia e noite, bem como interferometria de repetição da missão da Agência de Exploração Aeroespacial do Japão - JAXA (JAXA, 2019).

A partir dos dados altimétricos provenientes do sensor da JAXA, foi utilizado software ArcGIS 10.2 para processamento das 9 cenas (demais processamento), realizando a junção de todas as cenas (mosaico) para obter a área total de análise. Com o mosaico pronto, pode-se fazer os processamentos, iniciando pela reprojeção do mosaico, transformando para projeção SIRGAS 2000 UTM 22S, ou seja, em uma projeção plana.

Figura 1 - Mapa de localização da área de estudo.

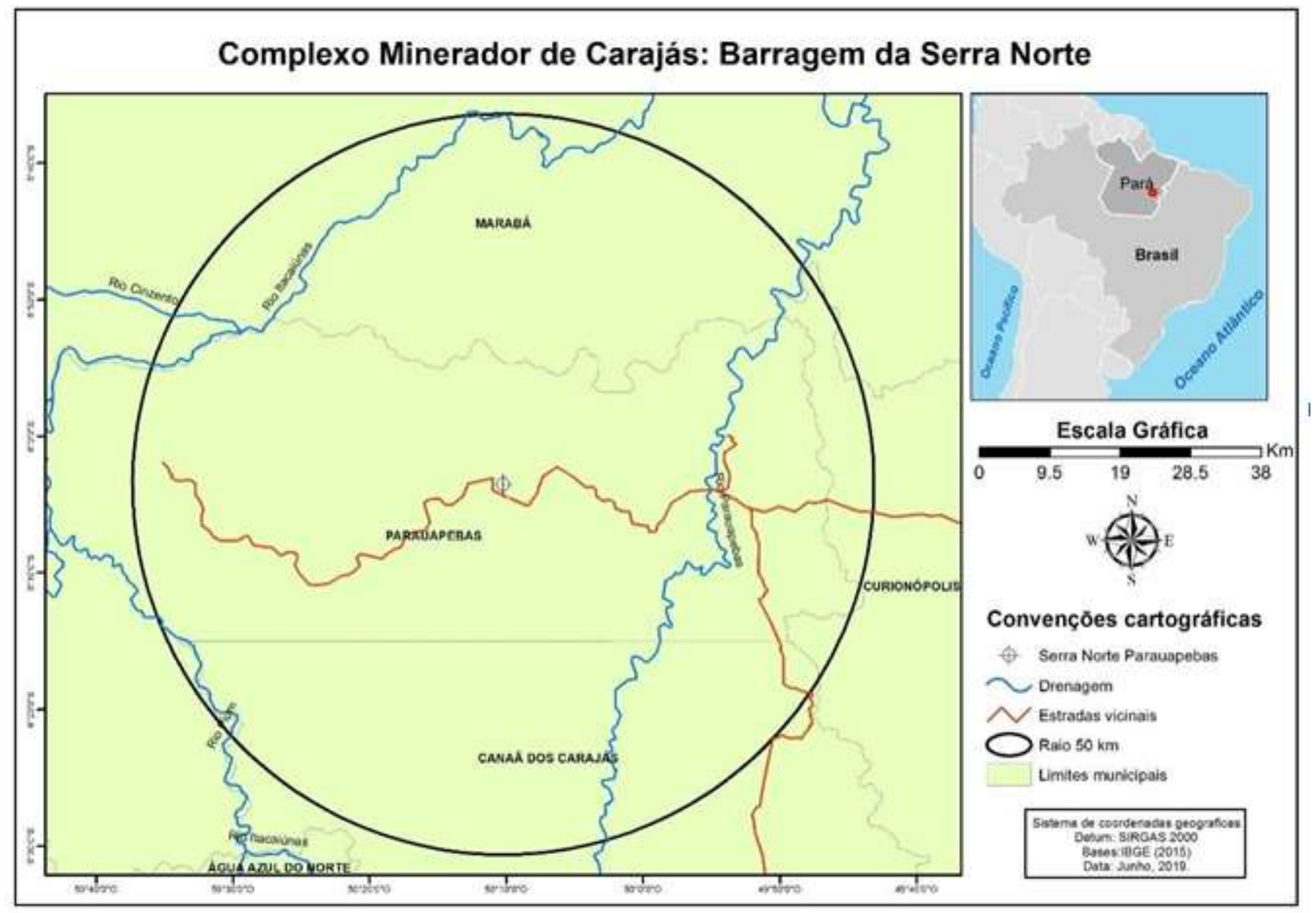

Fonte: Autores. 
Posteriormente foi realizado o tratamento na imagem, realizando o algoritmo de preenchimento de falhas para minimizar os erros decorrentes da imagem, com isso, pode-se realizar o algoritmo de direção de fluxo, que considera a altimetria do terreno para determinar para qual lado o fluxo vai, ou seja, de pontos mais elevados para pontos mais baixos.

Com isso, houve a implantação do algoritmo para cálculos de curvas de nível, sendo realizado o teste para curvas de nível com intervalo de 10, 20, 30, 40 e 50 metros, no qual, o mais indicado foi utilizar as curvas de nível de 20 metros para o próximo processamento, que foi a geração do modelo digital de elevação - DEM, utilizando o algoritmorede de triângulos irregulares - TIN.

Com a geração da direção de fluxo e do DEM, partiu-se para delimitação da área real de estudo, que definiu o ponto mais central da barragem de Serra Norte (maior barragem da região) e a partir do ponto foi aplicado uma área de interesse, testando de $50 \mathrm{~km} \mathrm{e} 80 \mathrm{~km}$ de raio, optando por utilizar a área de $50 \mathrm{~km}$ por ser suficiente para englobar até a cidade de Parauapebas e outras áreas consideradas importantes pelos autores.

Com a área definida, pode-se partir para elaboração dos produtos, utilizando também dados cartográficos do IBGE (2015) para produção dos mapas.

\section{Resultados e Discussão}

A barragem localizada na Serra do Norte, Parauapebas - PA, região Amazônica que conforme dito anteriormente possui abundancia em recursos naturais. Localidade rodeada de rios e diversos municípios de alta demanda demográfica, principalmente Parauapebas, possuindo 153.903 pessoas baseado no último senso. Com isso em raio de $50 \mathrm{~km}$, as populações atingidas em caso de acidente se tornam alto, e através da Figura2, observa - se o tamanho da extensão no qual afetará a vegetação local, no caso Parauapebas, e outras regiões (IBGE, 2010).

Figura 2 - Modelo digital de elevação no raio de $50 \mathrm{~km}$ da barragem Serra do Norte - Parauapebas.

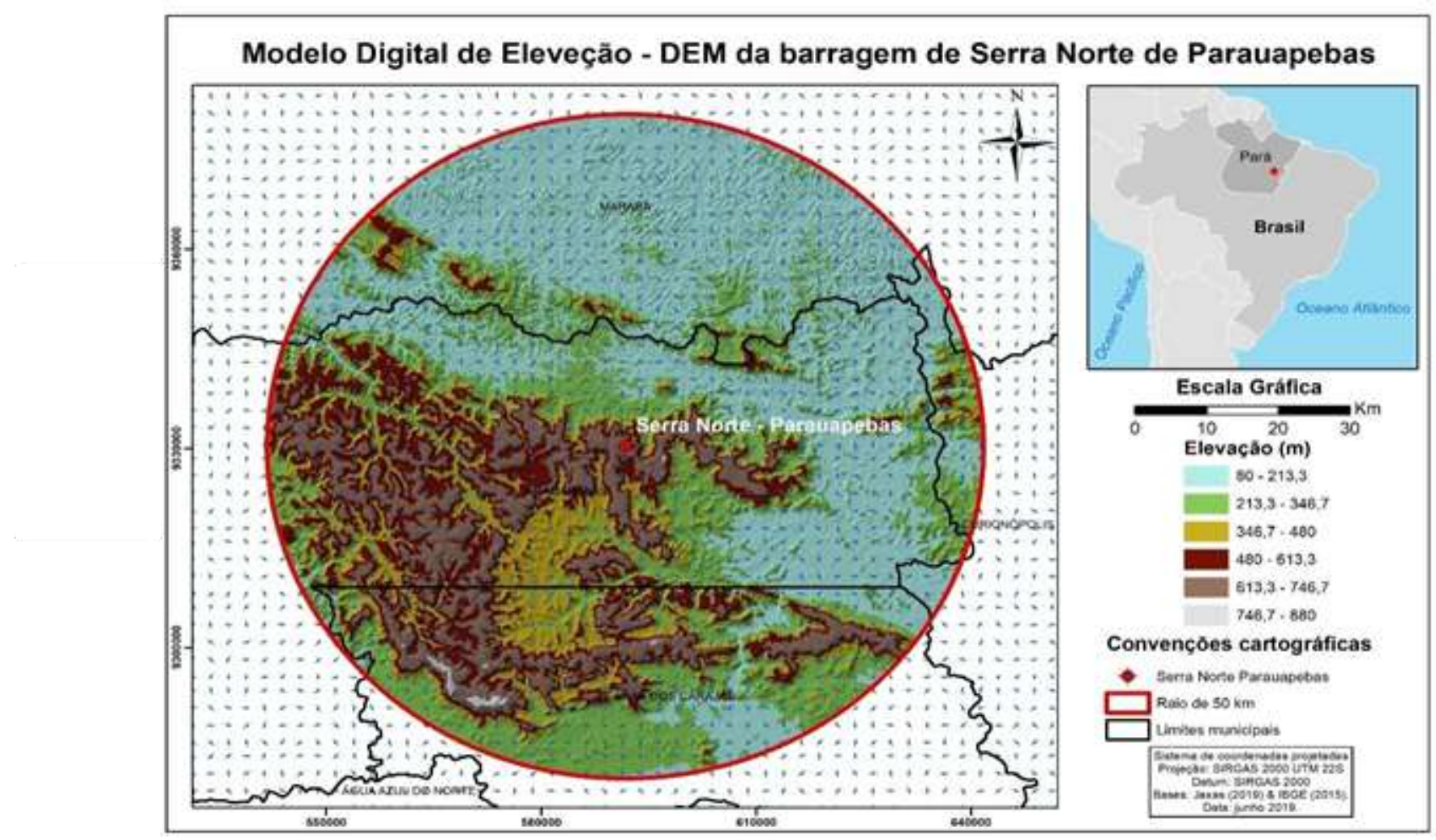

Fonte: Autores. 
Segundo a Figura 2 observa-se também, o sentido dos fluxos que vão do ponto mais alto até o mais baixo de acordo com a elevação do terreno. A barragem de rejeitos de minério de ferro está no centro geográfico do município de Parauapebas e nas suas mediações abrange os municípios de marabá, Canaã de Carajás e Curionópolis. Na região de marabá os valores da elevação do terreno foram inferiores aos valores de Parauapebas, onde está instalada a barragem de rejeitos de minério de ferro.

Significando que em caso de rompimento a área afetada, primeiramente será Parauapebas pelo fato da sua localização, logo após as cidades de Marabá e a região de Canaã, de acordo com os tipos de elevação demonstrados no mapa. Nesta região existem estradas vicinais onde possuem moradores e edificações. Sendo assim, o dano nesta área será de alto grau, causando transtornos, destruindo edificações com lançamento da lama contendo metais pesados, que irão contaminar o solo e o lençol freático. Vale ressaltar que a elevação na região de Canaã de Carajás é alta, podendo contribuir para direcionar o fluxo de lama para o rio Parauapebas e assim causar assoreamento do rio que corta os dois municípios.

Corroborando com Carneiro (2018), dano Potencial Associado, ou DPA, é o dano que pode ocorrer devido ao rompimento, vazamento, infiltração no solo ou mau funcionamento de uma barragem, independentemente da sua probabilidade de ocorrência, podendo ser graduado de acordo com as perdas de vidas humanas e impactos sociais, econômicos e ambientais. Para Carneiro (2018), o lançamento de rejeitos de minério de ferro no corpo hídrico tem como consequência a eutrofização deste corpo receptor, uma vez que, altas concentrações de metais pesados estarão presentes tais como: $\mathrm{Pb}, \mathrm{Cr}, \mathrm{Ba}$ e $\mathrm{Al}, \mathrm{Fe}, \mathrm{Mg}$, Ni, Zn entre outros( Silva et al 2017, Ferreira et al 2018). Correlacionando com autores (Santos et al 2018, Silva et al 2020, Faria \& Blanco 2020), os componentes químicos afetam a qualidade e disponibilidade da água, ar, vegetação, fertilidade e microbiota do solo. Estes impactos são ocasionados tanto pelo acúmulo de sedimentos, quanto pela sua toxicidez, principalmente devido à presença de aminas, elevando o $\mathrm{pH}$ da água e solo, além de causar algum dano, tanto a saúde individual ou coletiva, quanto a degradação ao meio ambiente.

Diante disso, o prognóstico das consequências socioambientais do acidente é, portanto, estarrecedor. Quando a lama de rejeitos secar, o solo ficará impermeabilizado e sem nenhum tipo de matéria orgânica. Segundo Lopes (2016), sem os nutrientes necessários não haverá tentativa de resiliência nem de sucessão por parte da vegetação. $\mathrm{O}$ assoreamento dos cursos d'água, com suas nascentes e margens, será inevitável. Todo o ecossistema local e sua biodiversidade serão drasticamente afetados.

Contudo, no que se refere à biodiversidade aquática e a qualidade das águas da bacia hidrográfica os danos causados pelo rompimento das barragens podem ser perversos e imensos, eis que proporcionais à extensão do corpo hídrico atingido pela lama. Em alguns casos, as perdas serão irreversíveis, haja vista a possível extinção de espécies consideradas endêmicas. Por onde a lama de rejeitos passar deixa um rastro de contaminação, mortandade e destruição (LOPES, 2016).

De acordo com o Vormittag, Oliveira e Gleriano (2018),a população é afetada em grau forte, passando por 3 (três) fases, sendo: Resgate com os efeitos mais agudos, momentâneos e entre minutos, horas e dias, como acidentes, afogamentos, lesões ou óbitos, Recuperação, consiste entre semanas e meses, como as doenças infecciosas, transmissíveis afetada pelo desastre por vetores ou não e a fase reconstrução, sintomas que surgem entre meses e anos, ou até antes, como as doenças comportamentais, psicológicas e mentais, sendo elas depressão, ansiedade, entre tantas outras.

Para Carneiro (2018), além da sociedade, é importante lembrar das espécies de animais e vegetais existentes na região, pois a diversidade poderá sofrer descontrole no ciclo e até mesmo a extinção. Segundo o autor a preocupação com o meio ambiente é mais do que um compromisso a ser assumido, é uma meta em curto prazo para que se tenham condições satisfatórias de vida humana no planeta. Dentre os cuidados dispensados com o meio ambiente, o gerenciamento de resíduos é uma das ferramentas-chave de responsabilidade das empresas que trabalham com produtos químicos ou outros que podem causar algum dano, tanto a saúde individual ou coletiva, quanto a degradação ao meio ambiente 
É importante observar que uma das consequências de rompimentos de barragens em uma região são os impactos que serão causados em outras regiões e suas consequências ao meio ambiente e na qualidade de vida da população. Uma vez que, o rejeito diluído da barragem ganha velocidade e tem capacidade de percorrer quilômetros. Sendo assim, se faz necessário que medidas sejam tomadas como pontos de remediação para que não ocorra um desastre físico, químico e biológico na região.

\section{Considerações Finais}

No âmbito regional, os efeitos da lama lançados em uma área coberta de residências impactam na moradia das pessoas que residem na região ou nas mediações que serão impactadas pelo rompimento da barragem, afetando a qualidade de vida e saúde dos mesmos.

Os lançamentos de rejeitos em um corpo hídrico ocasionam a contaminação dos rios e lagos que cortam o corpo receptor, afetando na qualidade desta água, contribuindo pela escassez ao consumo humano e influenciando diretamente nas atividades de pesca devido a mortandade de peixes e doenças decorrentes de metais pesados. O rompimento de barragens impacta nas atividades econômicas de geração de energia e indústria na região e entorno dela, pois muitos municípios são abastecidos (beneficiados) pela geração de emprego e renda que a barragem traz para região, além de impactar diretamente na economia da cidade e os costumes das populações tradicionais.

Sendo assim, diversos danos humanos e ambientais podem permanecer por um longo prazo, e ainda vários efeitos podem ser irreversíveis e de difícil gestão. Diante do exposto, o presente trabalho tem o intuito de servir como informativo, pois os dados apresentados são de grande valia para a população, órgão públicos e empresas responsáveis pelas barragens existentes no país, é medidas podem ser tomadas para evitar um desastre ambiental na região na Serra do Norte, Parauapebas PA.

Deve-se, portanto, fortalecer a legislação através de melhores práticas de governança, programas de monitoramento estruturados, rigorosidade nas leis ambientais, fiscalizações de órgãos ambientais competentes as atividades de barragens e liberação de licenças ambientais, entre outros.

\section{Referências}

Agência De Exploração Aeroespacial Do Japão - JAXA. (2019). Sobre O Alos Palsar. Https://www.Asf.Alaska.Edu/Sar-Data/Palsar/About-Palsar/.

Caitano, T. B. Dos S., Silva, E. R. P. Da, Alves, C. N. (2021). Caracterização e análise de segurança das barragens de mineração de ferro situadas no estado do Pará, Brasil. Research, Society and Development, 10(3), e35810313384. 10.33448/rsd-v10i3.13384.

Carneiro, G. S. G. (2018). Estudo Das Causas, Impactos E Medidas Corretivas Do Rompimento De Uma Barragem De Rejeitos, Usando O Caso Da Barragem De Mariana - Mg.Trabalho De Conclusão De Curso. Faculdade De Engenharia Civil - Ufu, Uberlândia.

Faria, L. P. C., Blanco, C. J. C. (2020). Emissão de poeira em pátio de estocagem de minério de ferro: uma abordagem ambiental e ocupacional. Research, Society and Development, 9(2), p. e05921873. 10.33448/rsd-v9i1.1873.

Ferreira, M. J., Cordeiro, J., Calazans, G. M., Santiago, G. L. A., Cordeiro, J. L., Guimarães, J. C. S. (2018). Percepção da população de São Gonçalo do Rio Abaixo (MG) acerca dos impactos socioambientais e econômicos desencadeados pela explotação de minério de ferro na mina de Brucutu. Research, Society and Development, 7(5), e275143. 10.17648/rsd-v7i5.180.

Guimarães, J. I. (2018). Impacto Do Rompimento De Uma Barragem De Rejeitos De Minério De Ferro Sobre A Qualidade Das Águas Superficiais. Estudo De Caso: Bacia Do Rio Doce. Dissertação De Mestrado. Programa De Pós-Graduação Em Saneamento, Meio Ambiente E Recursos Hídricos Da Universidade Federal De Minas Gerais.

Instituto Brasileiro de Geografia e Estatística - IBGE. (2010). Censo Demográfico - Parauapebas. https://www.ibge.gov.br/cidades-eestados/pa/parauapebas.html

Instituto Brasileiro de Geografia e Estatística - IBGE, (2015) "Bases Cartográficas”. https://www.ibge.gov.br/geociencias/cartas-e-mapas/bases-cartograficascontinuas/15759-brasil.html

Lopes, L. M. N. (2016). O Rompimento Da Barragem De Mariana E Seus Impactos Socioambientais.Sinapse Múltipla, 5 (1), 1-14.

Reis, D. A. Dos, Marques, L. De S., Nascimento, L. P. Do, Santiago, A. Da F. (2020). Potencial de risco dos sedimentos de fundo afetados por rejeitos de mineração oriundos da barragem de Fundão/ Brasil. Research, Society and Development, 9(7), e611974041. 10.33448/rsd-v9i7.4041. 
Ribeiro, E. Dos S., Faro, B. L. S. De O., Nascimento, R. S. C., Carneiro, F. Da S., Amaral, A. P. M., Bezerra, M. G. Dos S., Amorim, M. B., Garcia, T. De S. (2021). Avaliação multitemporal da cobertura vegetal da reserva biológica de Tapirapé, Pará. Research, Society and Development, 10(4), e50910414345. $10.33448 /$ rsd-v10i4.14345.

Rosário, R. R., Barbosa, M. T., Carneiro, F. Da S., Costa, M. Do S. S. (2021). Uso e ocupação do solo do município de novo progresso no Estado do ParáBrasil. Research, Society and Development, 10(1), e51210112060. 10.33448/rsd-v10i1.12060.

Scarpelin, J., Herculano, L. M. L., Dias, L. C. P., Chume, V. F. (2020). Rompimento de barragem e direito à moradia adequada: perspectivas do maior desastre socioambiental do setor de mineração Brasileiro. Research, Society and Development, 9(4), e80942517. 10.33448/rsd-v9i4.2517.

Silva, P. R. Da, Muller, R. F., Cordeiro, J. S. (2020). Análise dos impactos no uso e ocupação do solo associados a possível ruptura da Barragem do Itabiruçu, Itabira (MG). Research, Society and Development, 9(4), e93942863. 10.33448/rsd-v9i4.2863.

Silva, P. R. Da, Muller, R. F., Cordeiro, J. S. (2020). Análise dos impactos no uso e ocupação do solo associados a possível ruptura da Barragem do Itabiruçu, Itabira (MG). Research, Society and Development, 9(4), e93942863. 10.33448/rsd-v9i4.2863.

Silva, R. A. Da, Cordeiro, J., Bernardes, C. D., Alvarenga, C. A. De, Cordeiro, J. L., Calazans, G. M. (2017). Percepção da população do município de Santa Bárbara (MG) acerca da atividade minerária e da contaminação do solo e da água por arsênio. Research, Society and Development, 5(3),225-244.

Silva, S. A. Da, Azevedo, L. E. C. De, Lima, G. V. B. De A., Pereira, M. M., Araújo, I. R. S. (2020). Otimização estatística de parâmetros de qualidade de águas superficiais no monitoramento ambiental em atividades de mineração na Amazônia. Research, Society and Development, 9(3), e99932596. $10.33448 /$ rsd-v9i3.2596.

Sindicato Das Indústrias Minerais Do Estado Do Pará-Simineral. (2019). Mineração No Pará, Brasil E Mundo. http://Simineral.Org.Br/Mineracao/MineracaoPara.

Souza, C. B. G., Carneiro, F. Da S., Rodrigues, H. C. T., Ribeiro, E. G. P., Amaral, A. P. M., Silva, J. S. L. P. Da., Araujo, S. C. A., Castro, C. V. B. (2021), Análise espaço-temporal de Área de Proteção Permanente para a gestão ambiental municipal em Parauapebas no estado do Pará-Brasil. Research, Society and Development, 10(6), e24110615491. 10.33448/rsd-v10i6.15491.

Tavares, L. C., Costa, J. A. Da., Araújo, A. R. Da R., Garcia, F. H. M., Carneiro, F. Da S., Amaral, A. P. M., Braga, E. O., Garcia, T. De S. (2021). O uso do índice de vegetação por diferença normalizada na análise multitemporal da cobertura vegetal no complexo industrial do município de Barcarena-Pará-Brasil. Research, Society and Development, 10(7), e23010715470. 10.33448/rsd-v10i7.15470.

Thomé, R. \&Passini, M. L. (2018). Barragens De Rejeitos De Mineração: Características Do Método De Alteamento Para Montante Que Fundamentaram A Suspensão De Sua Utilização Em Minas Gerais. Ciências Sociais Aplicadas Em Revista - Unioeste/Mcr, 18(34), 49 A 65.

Vormittag, E. M. P. A. A, Oliveira, M. A. \& Gleriano, J. S. (2018). Avaliação Dos Riscos Em Saúde Da População De Barra Longa/Mg Afetada Pelo Desastre.Ambient. Soc. 21. 